
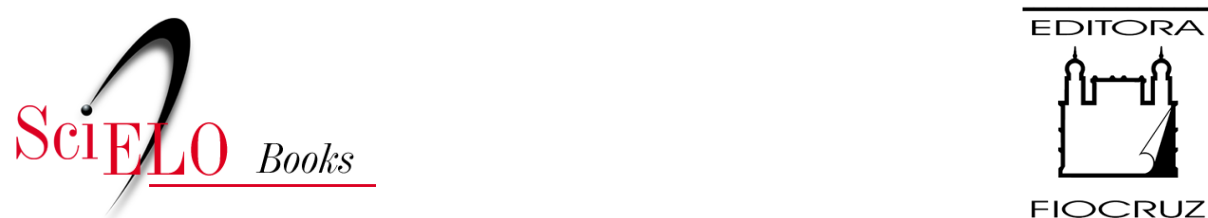

FIOCRUZ

\title{
7. Entre solidariedade e subsidiariedade
}

\author{
Lígia Giovanella
}

\section{SciELO Books / SciELO Livros / SciELO Libros}

GIOVANELLA, L. Entre solidariedade e subsidiariedade. In:

Solidariedade ou Competição? Políticas e sistema de atenção à saúde na Alemanha [online]. Rio de Janeiro: Editora FIOCRUZ, 2001, pp. 289302. ISBN: 978-65-5708-097-9.

http://doi.org/10.7476/9786557080979.0010.

(c) (i)

All the contents of this work, except where otherwise noted, is licensed under a Creative Commons Attribution 4.0 International license.

Todo o conteúdo deste trabalho, exceto quando houver ressalva, é publicado sob a licença Creative Commons Atribição 4.0.

Todo el contenido de esta obra, excepto donde se indique lo contrario, está bajo licencia de la licencia Creative Commons Reconocimento 4.0. 


\section{Entre Solidariedade e Subsidiariedade}

O panorama contemporâneo acerca do Seguro Social de Doença alemão traçado neste estudo completa-se nesta discussão final, com o exame de suas reformas da década de 1990, no que diz respeito ao seu impacto sobre o nível de garantia da proteção social à saúde e a estrutura do sistema de proteção.

A apreciação aqui realizada não pretende definir o nível de desestruturação ou manutenção alcançados nem os limiares para qualificar a proteção ou a desproteção. Sem a intençāo de definir tipologias ou níveis e limites de proteçāo, discutir-se-á brevemente a variação na cobertura populacional pelo Seguro Social de Doença (GKV) e as alterações na extensão da cesta garantida como modos de aproximação à situação atual da proteção social ao risco de adoecer. Em seguida, serão debatidas as possíveis repercussões das políticas de contenção na estrutura da proteção, a qual é definida por seus princípios constitutivos, em especial, o da solidariedade, com mais forte expressão no seguro social de doença, e por características básicas.

Mais do que a análise financeira, o aspecto principal para o exame de políticas de contenção na área da saúde é a avaliação de suas repercussōes na garantia da proteção social. Os principais efeitos negativos de políticas de contençăo podem manifestar-se como redução da proteção social - uma forma de privatização - e como aprofundamento de desigualdades nos esquemas de proteção - segmentação. O termo 'privatização' é aqui empregado com o significado de desproteção: erosão da garantia de cobertura do risco de adoecer coletiva e pública. ${ }^{3.53}$ A questão é em que medida o risco de adoecer deixa de ser coberto publicamente e passa a ser responsabilidade direta dos indivíduos. A 'segmentação', por sua vez, implica na garantia de proteção diferenciada entre grupos populacionais,

353 Privatização não se refere aqui, portanto, a processos em que empresas ou serviços de propriedade estatal são vendidos ou em que a prestação de serviços passa a ser atividade da iniciativa privada. 
estratificando-os segundo algum critério, seja devido à ocupação, seja ao nível de renda, cristalizando e produzindo desigualdades.

O impacto das medidas de contenção na amplitude (nível e extensão) da proteção social garantida pode ser estimado com base na análise da evolução recente da cobertura populacional e das alteraçōes na extensão da cesta garantida. Ao examinar esse impacto no direito social na última década, questiona-se a redução ou não de sua garantia (privatizaçāo) e o aprofundamento de desigualdades dos esquemas de proteção (segmentação).

\section{Interpupção da Inclusão}

Considerando-se a linha de inclusão/exclusāo por meio da proporçāo da população que tem proteção à saúde garantida de forma coletiva mediante o GKV, observa-se que o nível de proteção social não se altera expressivamente nas duas últimas décadas. Na Alemanha Ocidental, desde os anos de 1970, o nível de proteção pelo seguro social de doença se mantém próximo a $90 \%$ da populaçāo residente com ligeiras variações: a mais, nos anos 70, e a menos a partir dos anos 80 . A variação entre o maior e o menor nível de cobertura no período é inferior a $4 \%$, não sendo possível afirmar que ocorreu desproteção (gráfico 5).

Gráfico 7 - Evolução da proteção à saúde na Alemanha. Região Ocidental - 1970-1995

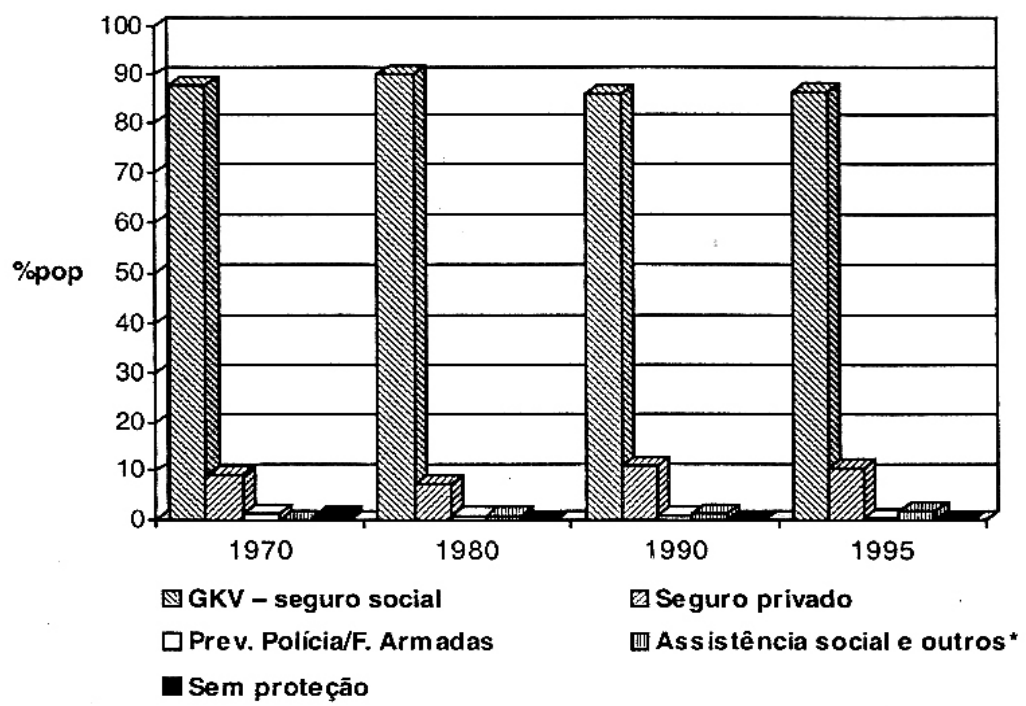

Fonte: SVR, 1994 T.300; StBA-Statistisches Bundesamt, 1980, 1990, 1995 (p.11; 47; 83), cálculos próprios. 
Observa-se, contudo, leve incremento da exclusão: cresce o número absoluto de pessoas protegidas apenas pela assistência social. Enquanto a população aumenta em cerca de $10 \%$ entre 1970 e 1995 , dobra o número de pessoas com acesso à atenção via assistência social. Embora tenha crescido, a proporçāo de beneficiários da assistência social no que concerne à proteção à saúde é baixa, menor que $2 \%$ da população (tabelas 2 e 3 ). A exclusão decorreu mais do aumento da pobreza e do desemprego e menos de mudanças na estrutura de proteção. Em 1995, a proporção de segurados pelo seguro social na Alemanha foi similar à de 1970. Como o início dos anos 70 é considerado como ponto de corte que marca o fim da expansão dos welfare states, pode-se afirmar que não houve retrocesso. É muito difícil, assim, corroborar teses que anunciam o fim dos Estados de bem-estar.

No que tange às regras de 'inclusão/exclusão', um exame do impacto das reformas das últimas décadas em relação à segmentação de clientelas mostra que o processo de inclusão de novos grupos ocupacionais na proteção, propiciada pelo seguro social de doença alemão, mantém seu padrão de inclusāo progressiva até $1981,{ }^{354}$ podendo-se fazer um paralelo de sua interrupção com a entrada da coalizão conservadora-liberal no poder em 1983 e sua saída em 1998. Este processo avançara após a Segunda Guerra Mundial e foi intenso ao final dos anos 60 e início dos 70. Em 1989, porém, com a Lei da Reforma da Saúde, foram aprovadas regras que limitaram a participação no GKV. Tais restriçōes atingiram, entre outros, o asseguramento dos aposentados, tornando-o dependente de um período de contribuição anterior mais longo sob argumento fundado no princípio de equivalência, ou seja, apenas quem contribui de forma regular para o sistema pode participar quando aposentado. Dificultou-se também a continuidade de asseguramento para profissionais autônomos, além da liberação dos operários com salários acima do limite de contribuiçāo da obrigatoriedade de asseguramento. ${ }^{3.5}$ Essa lei intẹrrompeu o processo de inclusão ao restringir a participação desse grupo no seguro social de doença.

Com a tomada de posse de nova coalizão govemamental social-democrata/ verde no governo central ao final de 1998, o processo de inclusão foi retomado, ampliando-se a participaçäo nos seguros sociais a contingentes até então excluídos, os(as) trabalhadores(as) de tempo parcial em 'ocupaçāo mínima'. ${ }^{356}$

354 Vide capítulo 2.

$355 \mathrm{O}$ último item é visto como abolição de privilégios dos empregados: ampliaçāo dos direitos dos operários que, recebendo salários mais elevados, poderiam optar pelo seguro privado, o que é vantajoso apenas para jovens solteiros e bem remunerados. Neste caso, como o risco é baixo, os prêmios a pagar são mais baixos do que as contribuições do GKV, proporcionais aos salários.

356 Embora a medida visasse também a ampliar as receitas dos seguros sociais, pois parte do contingente de trabalhadores incluídos, na maioria mulheres, desfrutava de benefícios na condição de dependentes sem contribuir, é possível afirmar, ao menos provisoriamente, a retomada do processo de inclusão. 


\section{Fim da Segmentação?}

As três etapas da 'reforma da saúde' (GRG, GSG e NOG) provocam impacto diferenciado na segmentaçāo. A 'Lei da Reforma da Saúde' (GRG) afeta a linha que define aqueles que estão ou não incluídos, ou seja, retrai a fronteira da inclusão. A Lei da Estrutura da Saúde (GSG) rompe com a imposição de segmentação entre os incluídos, até então existente, ao ampliar a liberdade de escolha das Caixas pelos segurados antes obrigados a filiar-se a Caixas específicas conforme a inserção profissional e/ou ocupacional.

As Leis de Reordenação da Saúde (NOG), de 1997, por sua vez, poderiam vir a produzir, no interior do sistema, uma nova segmentação das clientelas, influenciada mais claramente pelo nível de renda.

Caso o conjunto de opçōes para mudanças no estatutos das Caixas possibilitadas pelas NOGs fosse implementado de forma diferenciada pelas Caixas, a tendência seria de nova segmentação de clientelas: Caixas compostas por contribuintes de camadas mais bem remuneradas, jovens e com expectativa de consumo em saúde mais sofisticada/ampliada e Caixas de camadas pior remuneradas e de segurados mais idosos.

A situação de ter uma clientela de segurados mais jovens e bem remunerados, porém, não é de todo vantajosa para uma Caixa, em virtude da vigência da compensação financeira da estrutura de riscos. Caixas com estrutura de riscos de seus segurados mais favorável são sobrecarregadas nas transferências para o fundo de compensação.

Uma estratificação das Caixas segundo nível de renda, risco e morbidade, porém, não seria novidade no seguro social de doença alemão, pois, tradicionalmente, as Caixas tinham clientelas fechadas adscritas por profissāo, o que tem certa correlaçăo com o risco de adoecer e com a renda dos contribuintes. A competiçāo antes existente entre Caixas Locais e Substitutas pela adesão dos 'empregados" e segurados voluntários já denotava este tipo de estratégia para atrair segurados de baixo risco e renda alta. A compensação da estrutura de riscos, todavia, refreia esse tipo de competição. A instituição da compensação financeira da estrutura de riscos pela GSG foi, sem dúvida, uma das principais medidas para evitar concorrência predatória entre as Caixas e preservar a solidariedade básica no sistema.

Talvez seja mais adequado dizer, portanto, que a tendência aponta, a longo prazo, para a reintroduçāo de privilégios, definidos não mais apenas de acordo com a categoria profissional, mas também conforme a renda. Os resultados da implementação dos cortes do auxílio-doença introduzidos com o Sparpaket mostram que se amplia o campo ao retorno de privilégios à medida que se reduz o padrão legal estipulado. Ao transferir-se a disputa para a arena de 
negociação de acordos coletivos, local de expressão do conflito capital-trabalho, expandem-se as possibilidades de direitos diferenciados e de introduçāo de privilégios conforme a posição na ocupação. Desse modo, as desigualdades de direitos/benefícios entre categorias profissionais/ramos da produção conforme sua importância no procesșo de acumulação e grau de organização política, característica do modelo de seguro social (meritocrático-corporativo ou conservador) de proteção social, podem vir a ser reatualizadas.

Emprego os termos 'reatualização' e 'reintrodução', pois, com a evolução do seguro social, os privilégios de algumas categorias desapareceram por meio da ampliação progressiva de direitos/benefícios dos grupos de trabalhadores menos privilegiados, tendo sido atingida, em alto nível, a garantia de direitos similares entre os incluídos. Os welfare states não resolveram - e nem poderiam - o problema da estratificação social. Definiram limites, patamares comuns de garantia de necessidades básicas e padrões de vida digna, mas não aboliram as desigualdades sociais fundadas nas relações capitalistas de produção.

Ao longo do tempo, esvaeceram-se as características de segmentação do modelo de seguro social de tratamento desigual entre operários e empregados, relativas à conservação de status diferenciados e, como resultado, de direitos diferenciados. Em especial, no Seguro Social de Doença, a uniformização gradual em termos organizacionais e em relação aos direitos garantidos, ${ }^{357}$ a inclusāo progressiva de camadas populacionais cada vez mais abrangentes, bem como a ampliação do catálogo de ações garantidas à quase totalidade de ações médico-terapêuticas socialmente disponíveis tornaram os direitos semelhantes.

De fato, a maioria da população permanece incluída, e a segmentação ao interior dos incluídos foi atenuada, com a Lei da Estrutura da Saúde (GSG), ao expandir a liberdade de escolha a mais de $80 \%$ dos contribuintes. Além disso, o mecanismo de transferências financeiras entre as Caixas para a compensação da estrutura de riscos ampliou a redistribuição e, por conseqüência, a solidariedade. A redistribuição entre o conjunto dos segurados do GKV foi dilatada. Da solidariedade quase restrita aos membros de cada Caixa, a redistribuição estendeu-se ao conjunto dos segurados, inicialmente em separado para as Regiões Ocidental e Oriental. A Lei para Adaptação do Direito no GKV, aprovada em dezembro de 1999 pela coalizâo social-democratas/verdes, com o apoio da democracia cristã da região oriental, prevê a unificação progressiva da compensação financeira da estrutura de riscos entre as duas regiões. A redistribuição, assim, será expandida para o Seguro Social de Doença como um todo.

357 Para Döhler (1994), a amplitude e rapidez da expansão pode ser creditada, em parte, às diferenças com os empregados, como parâmetro à reivindicação da garantia de benefícios em igual nível. 
A ampliação da liberdade de escolha das Caixas pelos segurados corresponde simultaneamente à ampliação dos direitos dos segurados ao uniformizar as regras de adscriçāo. ${ }^{358}$ A possibilidade de asseguramento em uma ou outra Caixa deixou de ser atributo do status profissional. A garantia de liberdade dessa escolha, até então privilégio dos empregados, white collars, e a instituição de critérios idênticos para ambos os grupos, white collars e blue-collars, quanto à obrigatoriedade de asseguramento (introduzida com a Lei da Reforma da Saúde) dissiparam as distinções anteriores entre estes grupos.

Assim, se até os anos 80 pode-se dizer que o sistema foi conservado quase na íntegra, esta mudança ocorrida na década de 90 pode ser caracterizada como estrutural, pois interfere-se na forma de organização do sistema de provisão de seguros ao abolir-se, em grande parte, os critérios ocupacionais para a adscrição de clientelas.

Com a compensação da estrutura de riscos entre as Caixas houve certa aproximação das taxas de contribuição, atenuando-se desigualdades entre grupos ocupacionais. $\mathrm{O}$ grande intervalo de diferença existente entre as taxas de contribuição das distintas Caixas talvez tenha sido o principal resultado do modelo de proteção do Seguro Social de Doença que permaneceu após o processo de expansão. Mais do que garantir privilégios, diferenciando a proteção de distintos grupos, a persistência da forma de organização original de seguro produziu taxas de contribuição diferenciadas entre as Caixas, indicando que se exercia a solidariedade tradicionalmente apenas ao interior de cada grupo de segurados de uma Caixa. Estas importantes diferenças nas taxas de contribuiçăo contradiziam o princípio da solidariedade, segundo o qual cada um deve contribuir de forma proporcional a sua renda. Segurados com igual renda, mas adscritos a diferentes Caixas, contribuíram tradicionalmente (e ainda contribuem) com montantes díspares. Com esta redução de diferenças entre as taxas de contribuição, reduzem-se desigualdades.

A eliminação de privilégios amplia a solidariedade ao interior do sistema. A compensação da estrutura de riscos, por sua vez, faz com que a solidariedade extrapole o grupo de segurados de cada Caixa. $\mathrm{O}$ sistema permanece restrito ao mundo do trabalho assalariado, cristaliza-se aí, pois a solidariedade é pouco ampliada a grupos externos, mas a redistribuição transpõe, em parte, as barreiras de cada um dos grupos antes adscritos de modo compulsório a determinado tipo de Caixa, dependendo de sua ocupação. Atenua-se assim, a segmentação.

358 Parte da esquerda posicionava-se contra a liberdade de escolha das Caixas. A afiliação compulsória era vista como garantia de defesa de um coletivo, como barreira para atomização dos segurados. Não era compreendida como abolição de privilégios. Estes já teriam sido extintos com a constituição de catálogo único pela GRG. 


\section{Yível de Droteção: privatização parcial $e$ indireta do risco de adoecer}

Mais do que influir na segmentação, o que ocorre sāo restriçōes na utilização, uma vez que, além de diversos cortes de ações, introduziram-se uma série de medidas que podem ser tipificadas como de 'racionalização da demanda'.

As modificações do catálogo na última década, todavia, não podem ser enquadradas apenas em uma categoria de restriçōes. Na primeira etapa da reforma, em 1989, o catálogo foi uniformizado, o que significou ampliação de benefícios oferecidos anteriormente apenas por algumas Caixas ao conjunto dos segurados do GKV. Durante os anos 90 , novas ações foram incluídas simultaneamente às restriçōes. A cesta foi acrescida de açōes preventivas e profiláticas (na área odontológica), o acesso direto à psicoterapia foi garantido (deixou de ser intermediado pelo médico) e novo ramo de seguro para cuidados de longa duração foi criado, alargando-se a proteção social para novos riscos até então parcialmente cobertos.

Ainda que uma cesta básica não tenha sido definida nem importantes restrições introduzidas, mantendo-se o catálogo existente como único, uma série de cortes de pequena magnitude foi feita em diversas áreas da atenção à saúde, em geral, não relacionada à assistência médica ambulatorial e hospitalar diretas, sistematicamente protegidas.

As mais importantes restrições foram implementadas nos setores de assistência farmacêutica e atenção odontológica, em particular, por meio do aumento da participação financeira direta dos usuários. Estabelecidas em 1977, as regras de co-pagamento para medicamentos e próteses foram modificadas de maneira reiterada na última década, da mesma forma que majorada a participação dos usuários. De maneira específica, para a assistência farmacêutica, os aumentos dos valores de co-pagamentos na última década podem ser interpretados como redução da cesta de medicamentos até então garantida. ${ }^{359}$

$\mathrm{Na}$ assistência farmacêutica, o aumento das taxas de co-pagamento tradicionalmente nāo teve a oposição da indústria setorial nem das farmácias. Valores baixos de co-pagamento não afetavam diretamente o consumo, pois a demanda por medicamentos é secundária e, ao mesmo tempo, a introdução do copagamento para medicamentos teria contribuído para expansão do consumo e preços ao garantir a continuidade de seu financiamento. ${ }^{360}$ Após a majoração

$359 \mathrm{Em}$ todos os países da Uniāo Européia, com exceçăo da Holanda, existe co-pagamento para medicamentos (BMAS, 1996b). Estima-se que a participação financeira direta da população da Alemanha na assistência farmacêutica (considerados gastos totais), seria maior do que $50 \%$, situando-se em posição média em termos de comparação internacional.(OECD, 1997).

$360 \mathrm{Em}$ vez de levar à redução do consumo, o co-pagamento teria possibilitado às farmácias $\mathrm{e}$ indústria farmacêutica elevarem seus preços. 
pelas Leis NOG, em 1997, a indústria farmacêutica passou a reclamar dos altos valores atingidos, o que pode ser indicativo da previsão de impacto negativo sobre o consumo.

No caso da assistência odontológica, os cortes foram mais drásticos. A principal restrição implementada diz respeito às próteses dentárias. A cobertura dessas despesas pelas Caixas, que era de $80 \%$ em 1977, foi reduzida aos poucos, atingindo 50\% no início dos anos 90 . Em 1996, as próteses dentárias foram excluídas do catálogo para os segurados nascidos a partir de 1979 (os menores de 18 anos à época), exclusão esta posteriormente abolida pelos social-democratas. Em 1997, para os outros segurados, foi aprovada a substituição da participação percentual no pagamento de próteses por subsídio fixo por tipos, correspondente a $45 \%$ dos preços médios de entāo. O estabelecimento de subsídio fixo, ao desvincular a participação financeira das Caixas do preço real, provavelmente levará a aumento das despesas a cargo dos segurados.

A predileção por cortes em próteses dentárias pode ser atribuída ao fato de que estas ações nāo fazem parte do núcleo duro da assistência à saúde, sendo benefício de incorporaçāo mais recente. Tornou-se obrigatório apenas em 1974 . Além disso, tais restrições nāo sofrem a oposição de dentistas, nāo afetam diretamente um setor da economia ou o emprego de algum grupo profissional e não apresentam forte apelo moral.

A terceira etapa da reforma, por meio das leis de Alívio das Contribuições de 1996 e de Reordenação (NOG) de 1997, pode ser tomada como ponto de acentuação das restriçōes e de interrupção do processo anterior de expansão progressiva do catálogo de açōes e benefícios do GKV, não apenas pelos cortes introduzidos, como também pela majoração expressiva e dinamização da participação financeira dos pacientes.

As restrições ao catálogo ocorreram, em especial, por meio de cortes quantitativos. A opção por cortes quantitativos é em geral preferencial em políticas de contenção por ser de mais fácil aplicação. É difícil selecionar com base exclusivamente em critérios médicos quais seriam as ações necessárias e quais as denecessárias para excluir as últimas do catálogo. Assim, mais do que racionalização, renúncia a ações com efeito duvidoso, houve um provável racionamento, renúncia a ações de efeito comprovado, ${ }^{361}$ dado que o co-pagamento atinge as açōes de forma linear sem distinção nos setores em que é aplicado.

Os cortes quantitativos da cesta, ainda que importantes, são atenuados pela existência de cláusulas que dispensam os segurados de baixa renda do co-pagamento, limitam o comprometimento da renda para o conjunto dos segurados e reduzem esta participação no caso de doentes crônicos.

361 Definições conforme Porzsolt (1996). Os limites entre racionalização e racionamento são tênues. 
Cortes qualitativos foram propostos para a terceira etapa, mas nāo aprovados. A renúncia à introdução de outros cortes propostos pela coalizão conservadora-liberal decorreu da intervenção de diversos atores e o seu debate demonstrou a amplitude da constelação de interesses envolvidos: econômicos, prestadores de serviços, profissionais da área, grupos de pacientes, associações de deficientes, familiares, entre outros.

A possibilidade de acesso a cestas diferenciadas é restrita, pois a legislação não permite muita variação nas ações a serem oferecidas. ${ }^{362} \mathrm{O}$ catálogo de serviços permanece único para a quase totalidade das açôes oferecidas, e uma diferenciação limitada é possível apenas no sentido de sofisticação da cesta, resultante mais da ampliação de métodos terapêuticos alternativos do que pela inclusão de tecnologia médica de ponta. $\mathrm{O}$ acesso à tecnologia médica, pelo menos no estágio atual de desenvolvimento, é garantido.

Em síntese, pode-se dizer que o catálogo de benefícios do Seguro Social de Doença alemão, apesar das restrições, continua abrangente e uniforme. O cerne da atenção médica hospitalar e ambulatorial não foi atingido e o acesso ao progresso da tecnologia médica está assegurado por lei. A possibilidade de diferenciação do catálogo entre as Caixas é modesta e as principais restriçōes ao catálogo foram de caráter quantitativo, via participaçāo financeira direta dos segurados.

Embora não abrangentes, cortes quantitativos da cesta representam privatização parcial do risco de adoecer. A privatização parcial dos riscos acarreta desproteção, erosão da garantia de cobertura coletiva e pública do risco de adoecer. Tem o sentido de declínio do nível de proteção social à medida que despesas com assistência à saúde deixam de ser cobertas pelo esquema público solidário e passam a ser responsabilidade privada dos indivíduos. A privatização da cobertura do risco de adoecer na Alemanha, contudo, é parcial e, em especial, indireta. Indireta, pois o grupo de indivíduos incluídos e protegidos não foi significativamente reduzido. Parcial porque apenas pequena parte das despesas com cuidados de saúde foi transferida aos pacientes no ato da utilização.

\section{Impacto nos Princípios Constitutivos}

Questão central na análise das repercussōes estruturais das medidas aprovadas é o impacto das políticas de contenção nos princípios constitutivos do seguro social e, no caso do Seguro Social de Doença, em especial, o princípio da solidariedade. Como exposto, as contribuições no Seguro Social de Doença não são relativas aos riscos de saúde individuais, mas sim às possibilidades financeiras de

362 Estima-se que a possibilidade de variação do catálogo é de apenas $10 \%$ das açōes. 
cada contribuinte, consistindo em uma proporção de seus salários. Deste modo, todos os segurados, independente dos valores de contribuição, têm direito a catálogo idêntico de ações de saúde, o que envolve redistribuição, cujo deslocamento financeiro se dá dos segurados de maior renda, solteiros e mais sadios ao pólo oposto.

$\mathrm{Na}$ proteção social fundada no modelo de seguro social, a centralidade no trabalho assalariado pressupõe que sejam transpostas características das relaçōes do mercado de trabalho para a base da política social, cristalizando desigualdades; ao mesmo tempo, o Estado Social nega, em parte, os mecanismos de mercado, ao assegurar a satisfaçāo de necessidades sociais politicamente definidas. Neste modelo de proteção, o objeto das disputas políticas está na adequação entre mérito e necessidade.

Embora estruturado com base no mérito, uma concepção de distribuiçāo está embutida em diversas áreas do seguro social. Necessidades politicamente definidas fazem parte da estruturação do sistema. Uma vez que o princípio da necessidade também se faz valer independente da capacidade de contribuição do indivíduo, a solidariedade toma força no interior do sistema. Portanto, não se pode subestimar o princípio de justiça distributiva conforme as necessidades que estão presentes no sistema de seguro social.

Há constante tensão entre os princípios constitutivos do seguro social (equivalência/mérito, solidariedade/necessidade e subsidiariedade). Enquanto a 'solidariedade' pressupōe redistribuição, a 'equivalência' dos benefícios às contribuiçōes, o direito a benefícios conforme o 'mérito', nega esta possibilidade, a ‘subsidiariedade', por sua vez, restringe a comunidade solidária. A solução encontrada para este conflito, assim como para as contradições inerentes ao somatório dos elementos de natureza distinta, civil, político e social da cidadania (Fleury, 1997), resulta da correlação de forças sociopolíticas em cada momento dentro dos limites da seletividade estrutural do Estado capitalista (Offe, 1984; EspingAndersen, 1990). O ponto de equilíbrio temporário entre a solidariedade e a subsidiariedade, bem como entre a solidariedade e a equivalência, é politicamente definido em cada conjuntura histórica.

No Seguro Social de Doença alemão impera o princípio da necessidade. Ao garantir a utilização de serviços de saúde a todos os segurados conforme a necessidade e independente do valor das contribuições, o Seguro Social de Doença subsume a equivalência à solidariedade. A precedência de tal princípio sobre o da equivalência atenua as características conservadoras do modelo de seguro social alemão de cristalização das desigualdades produzidas pela posição ocupada no mercado de trabalho. ${ }^{363}$

363 A concomitância do princípio da equivalência contribuiria para a estabilidade do Seguro Social de Doença. As áreas da proteção social financiadas coletivamente, onde as transferências e redistribuição sāo mais fortes, apresentam a tendência de, em períodos de contençăo, serem afetadas com mais facilidade do que aquelas em que os benefícios são calculados com base no nível de remuneração dos indivíduos (Alber, 1986; Blanke, 1996). 
A expansão e uniformização do catálogo de serviços e benefícios, assim como a progressiva inclusão de camadas cada vez mais abrangentes da população, acoplada às possibilidades de emprego quase pleno, deram feição universal ao sistema contemporâneo. Assim, o princípio da solidariedade suplantou historicamente os princípios de equivalência e de subsidiariedade. No processo recente de contençāo, contudo, ocorre revitalização dos últimos, emergindo tensões entre a garantia de proteção conforme o mérito ou a necessidade e entre as responsabilidades individuais e as da comunidade solidária.

Com as políticas de contenção de gastos, a discussão a respeito da subsidiariedade voltou a ter destaque e sua vigência foi reatualizada em decorrência da opção preferencial destas políticas por mecanismos de privatização da demanda, em especial na terceira etapa. ${ }^{364}$

A opção por estes mecanismos que penalizam pacientes e segurados de menor renda afeta os princípios básicos do Seguro Social de Doença, conquanto existam mecanismos que atenuem a participação direta nos gastos pelos usuários das camadas de renda mais baixa. Provoca impacto negativo sobre o princípio da solidariedade sob a alegação de fortalecer a subsidiariedade. Para o aumento da participação dos pacientes nos custos da doença, evoca-se a necessidade de fortalecimento da auto-responsabilidade de cada indivíduo, reativando a concepção de subsidiariedade prevalecente quando da instituição do seguro-doença ao final do século passado.

Na Alemanha, o chamamento da política neoconservadora ao aumento da responsabilidade individual, que implicaria a utilização mais racional dos serviços/benefícios sociais, é eufemismo que encobre o aumento da participação financeira direta dos usuários. ${ }^{365}$

A subsidiariedade constitui também apelo à defesa de maior autonomia das Caixas. Esta tem diferentes conteúdos. Para as Caixas, envolve a possibilidade de maior influência no próprio sistema de atenção à saúde, com controle sobre os prestadores, e de maior liberdade para o estabelecimento de contratos mais favoráveis com os próprios, em especial, na atenção ambulatorial monopolizada pelas associaçōes de médicos credenciados. Para a coalizāo liberal-conservadora, a defesa de maior autonomia das Caixas significa desregulação com a introdução de mecanismos de mercado.

Evoca-se a subsidiariedade para exigir maior responsabilidade das Caixas nos aspectos financeiros, isto é, sua adesão à premissa da estabilização das taxas de contribuição a qualquer preço. A assunção, pela coalizão conservadora-liberal, da

364 Conforme já analisado, a subsidiariedade dá margem a ampla variação no nível de garantia da proteção. Pode ser aventada para a defesa de maiores valores de co-pagamento ou para restrições no catálogo de benefícios, transferindo estas responsabilidades aos indivíduos.

36.5 A assistência social é a área de política social na qual a intensificação da seletividade da proteção mais se faz sentir. Isso pelo próprio caráter deste ramo da proteção social, externo e separado do sistema de seguros sociais, cujo princípio regente é a subsidiariedade da ajuda estatal. 
reivindicação das Caixas por maior autonomia sob o mote, precedência para a administração autônoma (Vorfahrt für die Selbstverwaltung), ao mesmo tempo em que significou a abolição de algumas regras unificadas de controle sobre os prestadores e a introdução de mecanismos para a competição entre as Caixas, foi acompanhada por fortes restrições da autonomia das Caixas quanto à definição das taxas de contribuição.

Talvez o maior problema das medidas restritivas esteja no estímulo que podem significar para a produção de mentalidade não solidária e de reforço à equivalência, ao reduzirem a segurança quanto à garantia da proteção futura. Isto viria somar-se a certa concepção tida como difundida entre os mais jovens acerca de estarem menos dispostos a pagar por benefícios dos mais idosos, a quebra do 'contrato intergeracional'. Este raciocínio não solidário, contudo, nāo confere com as representações mais difundidas sobre a solidariedade no Seguro Social de Doença. Os segurados reconhecem e avaliam como positiva a redistribuição que ocorre ao interior do sistema de proteção à saúde. Ao considerarem a redistribuição como primariamente intertemporal (da juventude para a velhice), mais do que interpessoal, e a indesejabilidade da mudança de posição (ninguém deseja ficar doente para utilizar mais serviços), faz com que a posição de contribuinte para o fundo solidário, que mais paga do que recebe, seja avaliada, pela maioria dos segurados, como positiva em contraposição a uma situação de necessidade de maior utilização e, por conseguinte, de beneficiado com a redistribuição (Ulrich, Wemken \& Walter, 1994).

Com a terceira etapa da reforma, a subsidiariedade foi reforçada por meio da coação à 'ampliação da responsabilidade individual'. Pelas leis de Reordenação da Saúde - NOG, foi imposto às Caixas o deslocamento de gastos para os segurados (majoração compulsória dos valores de co-pagamento no caso de aumento das taxas de contribuiçāo). Indícios de retorno da equivalência também puderam ser observados, uma vez que seria possível ocorrer um reordenamento dos segurados em Caixas com catálogos parcialmente diferenciados não apenas por profissão, mas por nível de renda, conforme discutido acima.

Desse modo, enquanto a subsidiariedade e a equivalência prevaleceram na origem do seguro social alemão e, historicamente, com os processos de inclusão e expansão do Seguro Social de Doença, o princípio da solidariedade suplantou o princípio de equivalência e o princípio liberal-cristão de subsidiariedade, no processo recente de contenção, estes princípios voltaram a ser reforçados. A discussão quanto à subsidiariedade retomou o destaque e sua vigência foi reatualizada, em particular, por meio de ampliação da participação direta dos usuários nos custos da atençāo via co-pagamento.

As reformas dos anos de 1990 abriram a possibilidade de modificaçōes mais profundas no sistema, em especial, a Lei da Estrutura da Saúde (GSG), ao implementar a competição entre as Caixas, abolindo a adscrição de clientelas, e as 
Leis de Reordenação (NOG), ao acentuarem as restrições, expressando tendência à erosão da solidariedade. De forma simultânea, as diversas compensaçōes para evitar competição predatória e limitar o comprometimento da renda individual com despesas de saúde e a seleção de riscos deixam ver a permanência e estabilidade do sistema.

Ainda que medidas restritivas possam afetar de modo negativo o princípio da solidariedade, o sucesso das políticas de contenção não implicaria na desestruturação do modelo de seguro. $O$ modelo de seguro social poderia permanecer estável, uma vez que a segmentação e a reprodução de desigualdades lhe são intrínsecas. Os princípios que regem o seguro social também contribuem para a estabilidade demonstrada pelo sistema. Sua base, sustentada em princípios contraditórios, fornece-lhe flexibilidade para admitir distintos graus de desigualdade.

O Seguro Social de Doença tem mantido alta aceitabilidade por parte da população. Os segurados, com base em suas experiências, consideram o GKV como arranjo institucional que lhes garante o acesso à adequada e competente atenção médica a qualquer momento e no futuro (Hinrichs, 1994). Esta aceitabilidade decorre não somente do nível de garantia de proteção proporcionado, como também de características intrínsecas a este tipo de seguro. No Seguro Social de Doença não há o perigo de outrem estar usufruindo do benefício que o próprio preferiria. Os segurados não têm interesse em usufruir dos benefícios, pois este decorre de piora do estado de saúde, situaçāo nāo desejada. Nesse sentido, ao contrário dos outros ramos do seguro, a situação de contribuinte não beneficiário no GKV é pretendida. Ao mesmo tempo, a expectativa da utilização futura torna desejável a redistribuiçāo que ocorre ao interior do sistema. 'A norma da reciprocidade geral serve para reconciliar o auto-interesse e a solidariedade' (Putnam apud Hinrichs, 1994). ${ }^{366}$

$\mathrm{Na}$ realidade, embora tenham ocorrido restriçōes, a proteção social ao risco de adoecer na Alemanha permanece ampla e invejável, garantindo atenção à saúde a $90 \%$ da população em todos os níveis de complexidade. O Seguro Social de Doença alemão é, portanto, um bom exemplo de como a proteção social no caso da saúde não foi desmantelada, mesmo que, reformas conservadoras tenham sido implementadas.

Perspectivas de reforço à solidariedade na Alemanha ressurgiram com a nova coalizão governamental social-democratas/verdes. Restrições introduzidas na terceira etapa foram abolidas e a concepção de 'competição solidária' foi assumida. O tenso equilíbrio entre os princípios do seguro social, campo constante de disputa, alcançou novo ponto de sustentação, no qual a solidariedade é revitalizada.

Talvez em nenhum outro campo social fique tāo evidente o valor ético da solidariedade e tāo imprescindível seu exercício. O maior desafio atual no campo da saúde, nāo apenas para a Alemanha, é deslocar os objetivos das políticas de

366 Este talvez seja contraponto ao efeitos de erosão da base de apoio para a solidariedade decorrente do maior individualismo da sociedade contemporânea. 
saúde desde a eficiência para a eqüidade e os do sistema de atenção desde a doença para a saúde. Seu sucesso requer que se possibilite a assunção coletiva de comportamentos mais saudáveis por meio da criação de condições econômicosociais adequadas, engendradas na revitalização da solidariedade como valor ético e moral, nobre produto do processo civilizatório que foi materializado nas instituições de bem-estar. 